\title{
Interaction of karrikinolide and ethylene in controlling germination of dormant Avena fatua $\mathbf{L}$. caryopses
}

\author{
Jan Kępczyński · Johannes Van Staden
}

Received: 13 June 2011/ Accepted: 5 March 2012/Published online: 28 March 2012

(C) The Author(s) 2012. This article is published with open access at Springerlink.com

\begin{abstract}
Caryopses of Avena fatua L. are dormant after harvest and germinate poorly at $20^{\circ} \mathrm{C}$. Dormancy was released by after-ripening the dry caryopses in the dark at $25{ }^{\circ} \mathrm{C}$ for 3 months. Karrikinolide (butenolide, 3-methyl$2 H$-furo[2,3-c]pyran-2-one, $\mathrm{KAR}_{1}$ ), in contrast to exogenous ethylene and the precursor of ethylene biosynthesis 1-aminocyclopropane-1-carboxylic acid (ACC), completely overcame dormancy. The effect of $\mathrm{KAR}_{1}$ was not affected by aminoethoxyvinylglycine (AVG), $\alpha$-aminoisobutyric acid (AIB) and $\mathrm{CoCl}_{2}$, inhibitors of ACC synthase and oxidase, respectively. 2,5-Norbornadiene (NBD), a reversible inhibitor of ethylene binding to its receptor, counteracted the stimulatory effect of $\mathrm{KAR}_{1}$. Ethylene, ethephon and ACC counteracted and AVG reinforced inhibition caused by norbornadiene. Inhibition due to norbornadiene, applied during the first 3 days of imbibition in the presence of $\mathrm{KAR}_{1}$, disappeared after transfer to air or ethylene. The obtained results confirm that $\mathrm{KAR}_{1}$ breaks dormancy and indicate that ethylene alone plays no role in releasing dormancy of Avena fatua caryopses. $\mathrm{KAR}_{1}$ probably did not relieve dormancy via the stimulation of ethylene biosynthesis. Some level of endogenous ethylene is probably required for ethylene action, which might be required for releasing dormancy by $\mathrm{KAR}_{1}$ or for subsequent germination of caryopses after removing dormancy.
\end{abstract}

J. Kępczyński ( $\square)$

Department of Plant Physiology, University of Szczecin, Wąska 13, 71-415 Szczecin, Poland

e-mail: jankepcz@wp.pl

J. Van Staden

Research Centre for Plant Growth and Development, School of Life Sciences, University of KwaZulu-Natal Pietermaritzburg, Private Bag X01, Scottsville 3209, South Africa

e-mail: rcpgd@ukzn.ac.za
Keywords Avena fatua L. · Butenolide . Caryopses · Ethylene · Karrikinolide . Primary dormancy $\cdot$ Germination

\section{Introduction}

It is well documented that smoke and smoke-water stimulate seed germination of many plant species from fire-prone and fire-free environments (Light et al. 2009). The role of smoke in releasing dormancy and accelerating germination has been extensively studied since the germination stimulant, a butenolide compound (karrikinolide, 3-methyl- $2 \mathrm{H}$-furo[2,3$c$ ]pyran-2-one, $\mathrm{KAR}_{1}$ ), was isolated from plant-derived smoke (Van Staden et al. 2004) and burned cellulose (Flematti et al. 2004). Several studies showed that seeds sensitive to smoke also responded to $\mathrm{KAR}_{1}$ (Light et al. 2009). There are also examples showing that $\mathrm{KAR}_{1}$ and smoke are not equally effective in all species. Smoke contains many compounds besides the $\mathrm{KAR}_{1}$, some of which may inhibit germination (Light et al. 2010). Both smoke and the $\mathrm{KAR}_{1}$ stimulate germination of partially dormant caryopses (seeds) of Avena fatua, an important widespread, persistent weed, which infests agricultural soils for several years (Adkins and Peters 2001; Kępczyński et al. 2006b; Daws et al. 2007; Stevens et al. 2007). This compound completely removed dormancy in A. fatua caryopses at $15-25{ }^{\circ} \mathrm{C}$ when used continuously (Kępczyński et al. 2010). $\mathrm{KAR}_{1}$ can also be effective if applied for shorter periods. It was also found that the stimulatory effect of $\mathrm{KAR}_{1}$ on dormancy release of these caryopses is associated with cell cycle activation (Kępczyński et al. 2010). The physiological role of $\mathrm{KAR}_{1}$ in the control of seed dormancy, especially in relation to plant growth regulators, is poorly understood. The only relationship that has received attention is between $\mathrm{KAR}_{1}$ and gibberellic acid. Ethylene can stimulate the 
germination of primary dormant seeds of several plant species (Kępczyński and Kępczyńska 1997; Matilla and Matilla-Vázquez 2008) and ethephon can stimulate germination of partially dormant A. fatua seeds (Adkins and Ross 1981).

In view of these considerations, $A$. fatua seeds were used as a model system to define the relationship between $\mathrm{KAR}_{1}$ and ethylene. We determined: (1) the response of caryopses to $\mathrm{KAR}_{1}$, ethephon, ethylene and the precursor of ethylene biosynthesis 1-aminocyclopropane-1-carboxylic acid (ACC); (2) the effect of inhibitors of ethylene biosynthesis aminoethoxyvinylglycine (AVG), $\alpha$-aminoisobutyric acid (AIB) and $\mathrm{CoCl}_{2}$ in the presence of $\mathrm{KAR}_{1}$; and (3) the effect of 2,5-norbornadiene (NBD) (which inhibits ethylene binding to its receptor) when applied alone or in combination with ethylene, ethephon, ACC or AVG in the presence of $\mathrm{KAR}_{1}$ on caryopses germination.

\section{Materials and methods}

Florets of Avena fatua L. were collected near Szczecin in Poland at the time of natural dispersal in July 2007. After collection they were dried in open air at room temperature for 7 days and then stored at $-20{ }^{\circ} \mathrm{C}$ until required. Under these conditions dormancy was maintained. One batch of florets was stored dry at $25{ }^{\circ} \mathrm{C}$ for 3 months to break dormancy. In all experiments dehulled caryopses (lemma and palea removed) were used.

\section{Germination}

Three replicates of 25 caryopses each were incubated in Petri dishes $(6 \mathrm{~cm})$ on Whatman No. 1 filter paper moistened with $1.5 \mathrm{ml}$ distilled water, $\mathrm{KAR}_{1}\left(10^{-10}, 10^{-9}, 10^{-8}\right.$ $\mathrm{M})$, ethephon $\left(10^{-4} \mathrm{M}\right)$, ethylene $\left(4.5 \times 10^{-7} \mathrm{M}\right)$, ACC $\left(10^{-4} \mathrm{M}\right)$, AIB $\left(3 \times 10^{-4}, 10^{-3} \mathrm{M}\right)$, AVG $\left(3 \times 10^{-4}\right.$, $\left.10^{-3} \mathrm{M}\right)$ or $\mathrm{CoCl}_{2}\left(3 \times 10^{-4} \mathrm{M}\right)$ applied alone or in combination with $\mathrm{KAR}_{1}$ at $20{ }^{\circ} \mathrm{C}$ in the dark. Germination was recorded every day over 5 days or after 5 days depending on the experiment. All manipulations were performed under a green safe light at $0.4 \mu \mathrm{mol} \mathrm{m}{ }^{-2} \mathrm{~s}^{-1}$. Protrusion of the coleorhiza $(2 \mathrm{~mm})$ was used as the criterium of germination.

\section{2,5-Norbornadiene (NBD) and ethylene treatment}

\section{Continuous treatment}

For NBD $\left(5 \times 10^{-5}, 10^{-6} \mathrm{M}\right)$ treatment, 3 uncovered Petri dishes with 25 caryopses on filter paper moistened with water, $\mathrm{KAR}_{1}, \mathrm{KAR}_{1}$ in combination with ethephon, $\mathrm{ACC}$ or AVG were placed in tightly sealed glass containers (2.6 L). Liquid NBD was applied by syringe onto pieces of filter paper placed under the cover of the container. The liquid evaporated completely. Caryopses were also incubated in water or $\mathrm{KAR}_{1}$ in an atmosphere containing ethylene or ethylene in combination with NBD.

\section{Preincubation in NBD}

The caryopses were preincubated in water or in a solution of $\mathrm{KAR}_{1}$ on Petri dishes in containers $(2.6 \mathrm{~L})$ with NBD for 3 days. Seeds were then transferred to fresh water or a solution of $\mathrm{KAR}_{1}$ and then incubated for the following 4 days in glass containers $(2.6 \mathrm{~L})$ with air or an atmosphere containing ethylene. In one experiment caryopses were first preincubated in the presence of $\mathrm{KAR}_{1}$ and NBD and were then transferred to air and $\mathrm{KAR}_{1}$ in combination with AVG.

\section{1-methylcyclopropene (1-MCP) treatment}

Powdered 1-MCP in concentrations producing 25, 75 or $100 \mu \mathrm{l} / \mathrm{l}$ gas, were placed in open glass vials suspended under the cover in $500 \mathrm{ml}$ glass containers with 3 Petri dishes each containing 25 seeds on filter paper moistened with KAR1. In order to liberate 1-MCP to the atmosphere, $2 \mathrm{ml}$ of sterile water were injected through the stopper into a vial containing powdered 1-MCP.

Statistical analysis

The average \pm standard deviation (SD) of three independent samples of 25 caryopses each are presented. Data were analyzed using one-way and two-way ANOVA (Statistica for Windows ver. 8.0, StatSoft Inc., Tulsa, Oklahoma, USA) to determine statistical differences between mean values $(p<0.05)$. Treatment means were then ranked by the Duncan's multiple-range test.

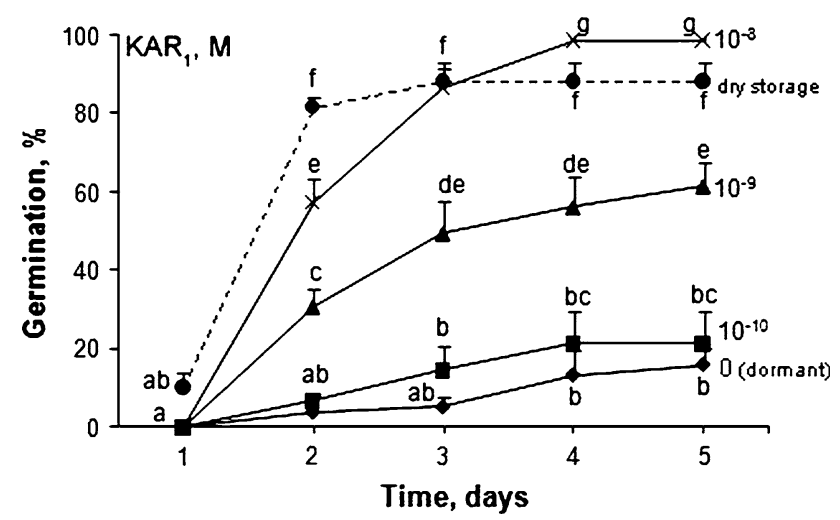

Fig. 1 The effect of $\mathrm{KAR}_{1}$ and dry storage for 3 months at $25{ }^{\circ} \mathrm{C}$ on the germination of A. fatua caryopses 


\section{Results}

Effect of dry storage and $\mathrm{KAR}_{1}$ on germination of caryopses

Germination of caryopses stored at $-20{ }^{\circ} \mathrm{C}$ (dormant) and dry-stored $\left(25^{\circ} \mathrm{C}\right.$ for 3 months) was determined (Fig. 1). Caryopses of A. fatua germinated poorly at $20^{\circ} \mathrm{C}$ after harvest; $17 \%$ after 5 days. Dry storage for 3 months allowed $80 \%$ of caryopses to germinate within 2 days and $90 \%$ after 5 days.

$\mathrm{KAR}_{1}$ at all concentrations used, stimulated germination of dormant caryopses. Even after 2 days a clear effect was observed; 30 and $60 \%$ of caryopses were germinated at $10^{-9}$ and $10^{-8} \mathrm{M}$ of $\mathrm{KAR}_{1}$ respectively. After 3 days $\mathrm{KAR}_{1}$ at $10^{-9}$ and $10^{-8} \mathrm{M}$ caused 50 and $85 \%$ germination, while at $10^{-8} \mathrm{M}$, the highest concentration used, $100 \%$ germination occurred after 4 days.

Effect of $\mathrm{KAR}_{1}$, ethephon, ethylene, ACC and inhibitors of ethylene biosynthesis on germination of dormant caryopses

Application of $\mathrm{KAR}_{1}$ at $10^{-8} \mathrm{M}$ resulted in all caryopses germinating after 5 days (Fig. 2). Ethephon, ethylene and the precursors of ethylene biosynthesis only had slight effects on germination.

To determine whether biosynthesis of endogenous ethylene is involved in the response of caryopses to $\mathrm{KAR}_{1}$, inhibitors of ethylene biosynthesis in combination with $\mathrm{KAR}_{1}$ were applied. Inhibitors of ACC synthase, $\alpha$-aminoisobutyric acid (AIB) and aminoethoxyvinylglycine (AVG), an inhibitor of ACC oxidase activity, did not affect the stimulatory effect of $\mathrm{KAR}_{1}$ (Table 1).

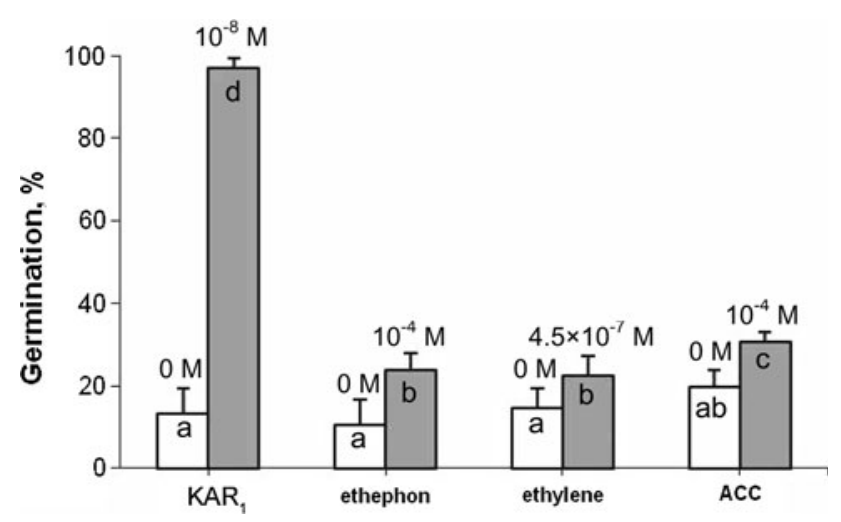

Fig. 2 The effect of $\mathrm{KAR}_{1}$, ethephon, ethylene and ACC on the germination of $A$. fatua $\mathrm{L}$. caryopses after 5 days
Table 1 The effect of $\mathrm{KAR}_{1}$ applied alone and in combination with AIB, AVG and $\mathrm{CoCl}_{2}$ on the germination of $A$. fatua caryopses after 5 days

\begin{tabular}{ll}
\hline Compounds, $\mathrm{M}$ & Germination (\%) \\
\hline $\mathrm{KAR}_{1}, 10^{-8} \mathrm{M}$ & $94.67 \pm 2.3$ \\
$\mathrm{KAR}_{1}, 10^{-8} \mathrm{M}+\mathrm{AIB}, 3 \times 10^{-4} \mathrm{M}$ & $97.33 \pm 2.3$ \\
$\mathrm{KAR}_{1}, 10^{-8} \mathrm{M}+\mathrm{AIB}, 10^{-3} \mathrm{M}$ & $88.00 \pm 4.0$ \\
$\mathrm{KAR}_{1}, 10^{-8} \mathrm{M}+\mathrm{AVG}, 3 \times 10^{-4} \mathrm{M}$ & $84.00 \pm 8.0$ \\
$\mathrm{KAR}_{1}, 10^{-8} \mathrm{M}+\mathrm{AVG}, 10^{-3} \mathrm{M}$ & $81.33 \pm 10.0$ \\
$\mathrm{KAR}_{1}, 10^{-8} \mathrm{M}+\mathrm{CoCl}_{2}, 3 \times 10^{-4} \mathrm{M}$ & $90.67 \pm 2.3$ \\
\hline
\end{tabular}

Germination of caryopses in the presence of 2,5norbornadiene and 1-MCP

The experiment with inhibitors of ethylene biosynthesis seem to suggest that ethylene is not part of the response of caryopses to $\mathrm{KAR}_{1}$. Consequently it was interesting to determine whether some action of ethylene is required for germination of dormant caryopses in the presence of $\mathrm{KAR}_{1}$. Therefore the competitive, reversible inhibitor of ethylene binding to its receptor, $5 \times 10^{-5} \mathrm{M}$ 2,5-norbornadiene (NBD), was applied. As in previous experiments germination of dormant caryopses incubated in water and air was
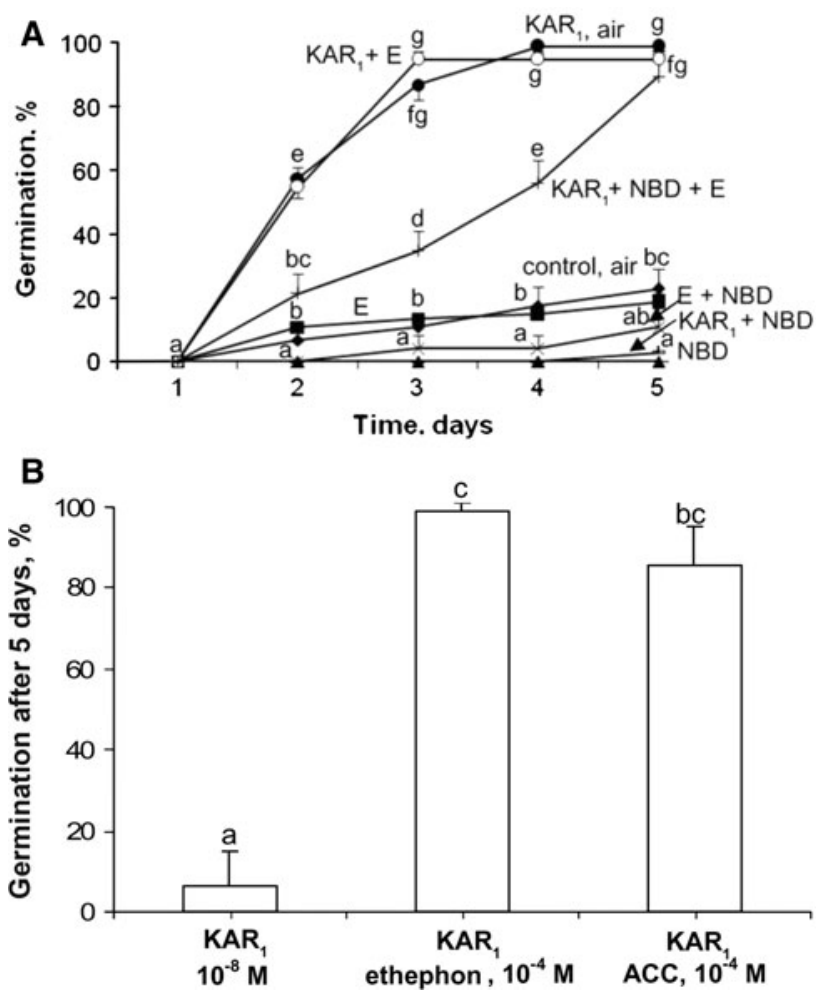

Fig. 3 The effect of $\mathrm{KAR}_{1}$ on the germination of $A$. fatua caryopses incubated in air, an atmosphere containing ethylene, 2,5-norbornadiene, a combination of norbornadiene and ethylene (a), or in the presence of ethephon or ACC in atmosphere with norbornadiene (b). $\mathrm{KAR}_{1} 10^{-8} \mathrm{M}$; NBD $5 \times 10^{-5} \mathrm{M}$; ethylene $4.5 \times 10^{-7} \mathrm{M}$ 
very low and after 5 days reached about $20 \%$, while $10^{-8} \mathrm{M}$ $\mathrm{KAR}_{1}$ caused germination of almost all caryopses (Fig. 3a). Addition of ethylene at $4.5 \times 10^{-7} \mathrm{M}$ did not affect germination of dormant caryopses either in the presence or absence of $\mathrm{KAR}_{1}$. Nobornadiene inhibited germination completely when caryopses were incubated in water and almost completely when incubated in a solution of $\mathrm{KAR}_{1}$. When caryopses were incubated in $\mathrm{KAR}_{1}$ and simultaneously in an atmosphere enriched with both NBD and ethylene, progressive germination during incubation was observed and after 5 days all caryopses had germinated. Likewise, incubation in the presence of $\mathrm{KAR}_{1}$ in combination with ethephon or ACC and in an atmosphere containing NBD, allowed all, or almost all, caryopses to germinate (Fig. 3b). Application of NBD at a far lower concentration, $10^{-6} \mathrm{M}$, did not completely block the stimulatory effect of $\mathrm{KAR}_{1}$ (Fig. 4). However, simultaneous incubation in NBD and $\mathrm{KAR}_{1}$ in combination with AVG caused greater inhibition of germination. Instead of the reversible inhibitor of ethylene binding, NBD, the non-reversible inhibitor of ethylene binding, 1-MCP, was applied simultaneously with $\mathrm{KAR}_{1}$ (Fig. 5). 1-MCP when applied with $\mathrm{KAR}_{1}$ at the lowest concentration $(25 \mu \mathrm{L} / \mathrm{L})$ decreased the speed of germination without affecting overall germination after 5 days of incubation. When the inhibitor was applied at $75 \mu \mathrm{L} / \mathrm{L}$ it markedly antagonized the stimulatory effect of $\mathrm{KAR}_{1}$ and only about $50 \%$ of the caryopses germinated. Application of MCP at $100 \mu \mathrm{L} / \mathrm{L}$ almost totally inhibited the stimulatory effect of $\mathrm{KAR}_{1}$ on germination.

Germination of caryopses preincubated in air enriched with 2,5-norbornadiene

To determine whether the NBD effect is toxic or non reversible, caryopses were preincubated in norbornadiene

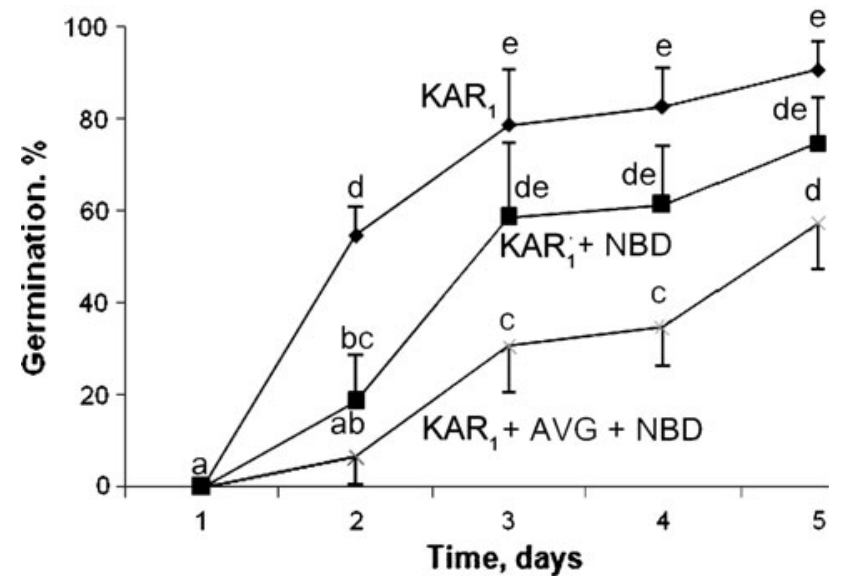

Fig. 4 The effect of $\mathrm{KAR}_{1}$ on the germination of caryopses of $A$. fatua in the presence of $\mathrm{AVG}$ and norbornadiene after 5 days. $\mathrm{KAR}_{1}$ $10^{-8} \mathrm{M}$; AVG $3 \times 10^{-5} \mathrm{M}$; NBD $10^{-6} \mathrm{M}$

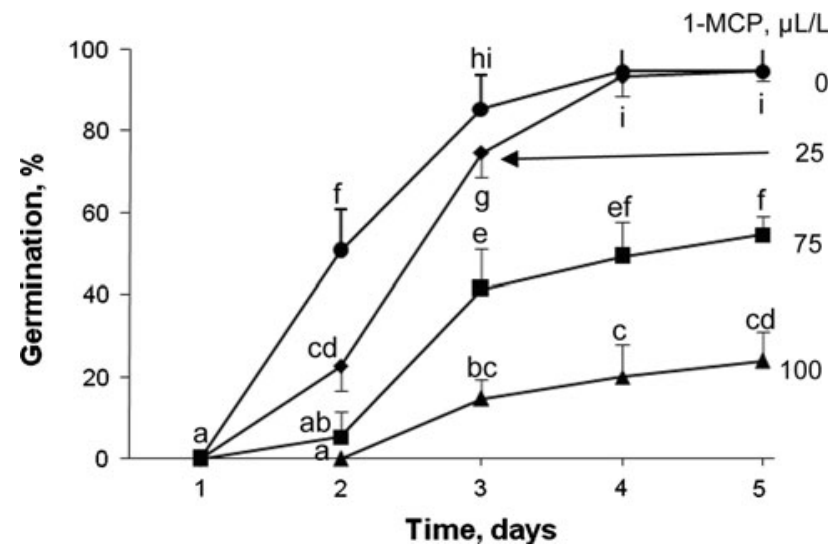

Fig. 5 The effect of $\mathrm{KAR}_{1}$ on the germination of $A$. fatua caryopses in the presence of $1-\mathrm{MCP}$
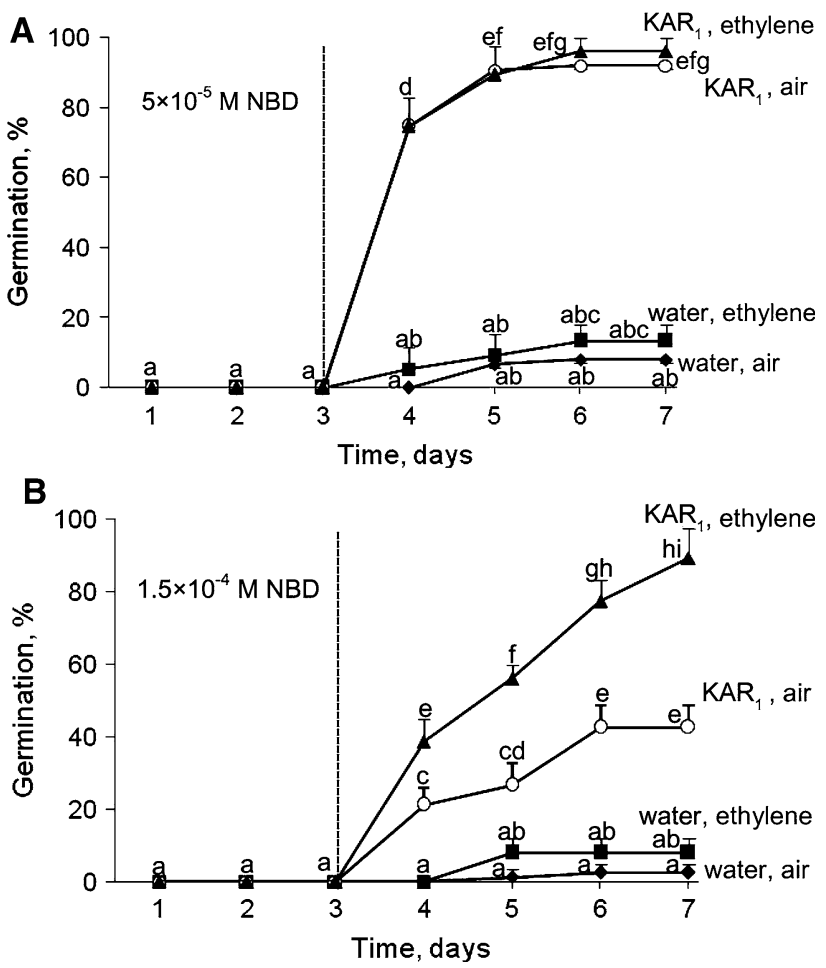

Fig. 6 The effect of transfer from norbornadiene to air or ethylene on the germination of A. fatua caryopses in the absence or presence of $\mathrm{KAR}_{1}$. The caryopses were incubated for 3 days in $5 \times 10^{-5} \mathrm{M}(\mathbf{a})$ or $1.5 \times 10^{-4} \mathrm{M}(\mathbf{b})$ norbornadiene and from days 3 to 7 in air or $5 \times 10^{-7} \mathrm{M}$ ethylene. The caryopses were incubated constantly with water or in the presence of $10^{-8} \mathrm{M} \mathrm{KAR}_{1}$

and in water or in a solution of $\mathrm{KAR}_{1}$ for 3 days and then transferred to fresh water or fresh solution of $\mathrm{KAR}_{1}$ and incubated in air or in an atmosphere enriched with ethylene (Fig. 6a). These caryopses did not germinate during preincubation in the presence of NBD. The inhibition of the stimulatory effect of $\mathrm{KAR}_{1}$ caused by preincubation in $5 \times 10^{-5} \mathrm{M}$ NBD was relieved completely after transfer to air. The addition of ethylene to the atmosphere after transfer 


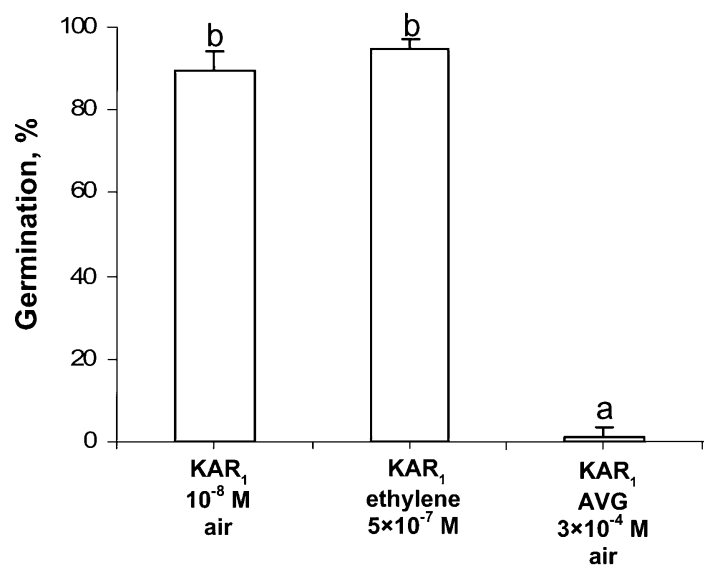

Fig. 7 The effect of transfer from an atmosphere enriched with norbornadiene to air or ethylene on the germination of $A$. fatua caryopses in the presence of $\mathrm{KAR}_{1}$ or $\mathrm{KAR}_{1}$ in combination with AVG. The caryopses were incubated for 3 days in $8 \times 10^{-5} \mathrm{M} \mathrm{NBD}$ and for 4 days after transfer in air or $5 \times 10^{-7} \mathrm{M}$ ethylene. The caryopses were incubated constantly in the presence of $10^{-8} \mathrm{M} \mathrm{KAR}_{1}$

did not accelerate the recovery of germination ability. When caryopses were preincubated in a solution of $\mathrm{KAR}_{1}$ and simultaneously at an higher concentration of NBD $\left(1.5 \times 10^{-4} \mathrm{M}\right)$ the inhibitory effect of norbornadiene was partially relieved after transfer to air and almost completely after transfer to an atmosphere containing ethylene (Fig. 6b). When caryopses were preincubated in the presence of $\mathrm{KAR}_{1}$ in an atmosphere together with $8 \times 10^{-5} \mathrm{M}$ norbornadiene for 3 days and then incubated simultaneously in the presence of $\mathrm{KAR}_{1}$ in combination with AVG, extremely low germination was observed (Fig. 7). Incubation in air or ethylene and simultaneously in the presence of $\mathrm{KAR}_{1}$, after transfer from norbornadiene, similarly as in the previous experiment, resulted in almost total germination.

\section{Discussion}

Seed dormancy is a relative phenomenon the expression of which varies with the environment. More dormant seeds germinate within a narrower temperature range than less dormant seeds and fully dormant seeds are not able to germinate at any temperature (Hilhorst 2007). It was shown that the optimal temperature for dormant Avena fatua caryopses is $4-12{ }^{\circ} \mathrm{C}$ with little germination at $20-24{ }^{\circ} \mathrm{C}$ while non-dormant seeds germinated at $4-24{ }^{\circ} \mathrm{C}$ (Naylor and Fedec 1978). In this study caryopses of Avena fatua that were air-dried and then stored at $-20{ }^{\circ} \mathrm{C}$, germinated poorly at $20{ }^{\circ} \mathrm{C}$, as in previous experiments (Kępczyński et al. 2010), $20 \%$. Dormancy of these seeds was removed by after-ripening during dry storage at $25{ }^{\circ} \mathrm{C}$ for 3 months (Fig. 1). In another experiment it was also demonstrated that dormancy in A. fatua caryopses can be released by dry storage at temperatures from 20 to $40{ }^{\circ} \mathrm{C}$ (Foley 1994). $\mathrm{KAR}_{1}$, isolated from plant-derived smoke, has the ability to stimulate germination of several plant species from fireprone and fire-free environments, including arable weeds and crop plants (Light et al. 2009). The observed stimulatory effect of $\mathrm{KAR}_{1}$ on germination of dormant $A$. fatua caryopses (Fig. 1) is in agreement with results shown previously (Daws et al. 2007; Stevens et al. 2007; Kępczyński et al. 2010) and indicates that stimulation by this compound is a common response for this species. Dormancy of A. fatua caryopses was removed in our experiments by $\mathrm{KAR}_{1}$ at very low concentration $\left(10^{-8} \mathrm{M}\right)$.

Ethylene, liberated from ethephon, applied as a gas or converted from the exogenous precursor of its biosynthesis, ACC, which was shown previously to increase ethylene biosynthesis in germinating dormant A. fatua caryopses (Kępczyński et al. 2006b) was not able to remove dormancy (Fig. 2). This is in contrast to the effect of $\mathrm{KAR}_{1}$ and indicates that ethylene does not play a role in controlling dormancy in A. fatua caryopses. This is in good agreement with previous findings, where ethephon increased germination only in partially after-ripened, but not fully dormant seeds of A. fatua (Adkins and Ross 1981). After-ripening induced sensitivity to ethylene also in Sisymbrium officinale seeds (Iglesias-Fernández and Matilla 2009). There are seeds where dormancy can be broken by ethylene (Kępczyński and Kępczyńska 1997; Matilla 2000). Some hypotheses suggest that ethylene acts minimally during dormancy inception and that its major action is during imbibition to terminate dormancy and/or initiate germination (Ghassemian et al. 2000; Matilla and Matilla-Vázquez 2008). Inhibitors of ACC synthesis, AIB, AVG as well as ACC conversion to ethylene and $\mathrm{CoCl}_{2}$ were not able to counteract the effect of $\mathrm{KAR}_{1}$ (Table 1). This may suggest that ethylene biosynthesis is not involved in the response to $\mathrm{KAR}_{1}$ during germination of dormant caryopses. Previously it was found that AVG did not affect germination of dormant $A$. fatua seeds in the presence of the dormancy breaking factor $\mathrm{GA}_{3}$ (Lalonde and Saini 1992). It was reported that inhibitors of ethylene biosynthesis did not affect germination of dormant sunflower embryos in the presence of cyanide, which breaks dormancy, and it was suggested that cyanide seed dormancy alleviation does not involve ethylene production (Oracz et al. 2008). The antagonism of the stimulatory effect of $\mathrm{KAR}_{1}$ by blocking ethylene binding to its receptor by norbornadiene (Fig. 3), might suggest that ethylene action is only involved in releasing dormancy by $\mathrm{KAR}_{1}$ or for the germination process after prior release of dormancy by this compound. The reversal of the inhibitory effect of norbornadiene on the release from dormancy by $\mathrm{KAR}_{1}$ suggests that ethylene binding to its receptor is required in caryopses response to karrikinolide. Likewise, results of experiments with the application of a non-reversible inhibitor of ethylene binding to its receptor, 
1-MCP (Fig. 5), which counteracted the stimulatory effect of $\mathrm{KAR}_{1}$ may confirm that ethylene action is necessary for germination of dormant caryopses. Previously it was reported that ethylene action is required in releasing primary and secondary dormancy of $A$. retroflexus and A. caudatus by gibberellin (Kępczyński et al. 2003; Kępczyński et al. 2006a). Antagonizing the stimulatory effect of $\mathrm{KAR}_{1}$ was also possible by combining NBD, at a concentration not completely blocking germination, with AVG (Fig. 4). This might suggest that a certain concentration of endogenous ethylene is required for germination of dormant caryopses in the presence of $\mathrm{KAR}_{1}$. Similarly as in other seeds (Kępczyński and Kępczyńska 1997) the effect of NBD was nontoxic and reversible), since inhibition of dormancy releasing by $\mathrm{KAR}_{1}$ as a result of preincubation in an atmosphere enriched with this inhibitor was relieved after transfer to air (Fig. 6a). Relieving inhibition after transfer to air is probably associated with the diffusion of NBD from the receptor and its replacement by endogenous ethylene. In cases where higher concentrations of NBD were used during pre-incubation of caryopses in a solution of $\mathrm{KAR}_{1}$, a slower recovery of germination ability after transfer to air (Fig. 6b) is probably related to a lack of sufficient amounts of endogenous ethylene required for expelling NBD molecules. Therefore exogenous ethylene effectively counteracted NBD-inhibition. The substitution of norbornadiene by endogenous ethylene, after transfer from a NBD atmosphere to air was impossible, because of the presence of AVG (Fig. 7), probably due to a lowering of ethylene biosynthesis.

The results presented here confirm that $\mathrm{KAR}_{1}$ is a very active compound for releasing dormancy in caryopses of $A$. fatua. Ethylene alone plays no role in control of the dormancy in the caryopses. Butenolide releases dormancy but not via stimulation of ethylene biosynthesis. A certain level of endogenous ethylene is probably necessary for ethylene action, which might be required for dormancy removing by $\mathrm{KAR}_{1}$ or for germination process after dormancy release.

Acknowledgments The study was supported by the Ministry of Science and Higher Education grants NN310151935 and NN726340. We also wish to thank Giovanni Regiroli and Andrea Cucchli of Rohm and Haas Company for providing 1-MCP and mgr Danuta Cembrowska-Lech for technical assistance.

Open Access This article is distributed under the terms of the Creative Commons Attribution License which permits any use, distribution, and reproduction in any medium, provided the original author(s) and the source are credited.

\section{References}

Adkins SW, Peters NCB (2001) Smoke derived from burnt vegetation stimulates germination of arable weeds. Seed Sci Res 11:213222
Adkins SW, Ross JD (1981) Studies in wild oat seed dormancy. I. The role of ethylene in dormancy breakage and germination of wild oat seeds (Avena fatua L.). Plant Physiol 67:358-362

Daws MI, Davies J, Pritchard HW, Brown NAC, Van Staden J (2007) Butenolide from plant-derived smoke enhances germination and seedling growth of arable weed species. Plant Growth Regul 51:73-82

Flematti GR, Ghisalberti EL, Dixon KW, Trengove RD (2004) A compound from smoke that promotes seed germination. Science 13:977

Foley ME (1994) Temperature and water status of seed affect after ripening in wild oat (Avena fatua). Weed Sci 42:200-204

Ghassemian M, Nambara E, Cutler S, Kawaide H, Kamiya Y, McCourt P (2000) Regulation of abscisic acid signaling by ethylene pathway in Arabidopsis. Plant Cell 12:1117-1126

Hilhorst HWM (2007) Definitions and hypotheses of seed dormancy. In: Bradford K, Nonogaki H (eds) Seed development, Dormancy and Germination. Blackwell, Oxford, pp 50-67

Iglesias-Fernández R, Matilla A (2009) After-ripening alters the gene expression pattern of oxidases involved in the ethylene and gibberellin pathways during early imbibition of Sisymbrium officinale L. seeds. J Exp Bot 60:1645-1661

Kępczyński J, Kępczyńska E (1997) Ethylene in seed dormancy and germination. Physiol Plant 101:720-726

Kępczyński J, Kępczyńska E, Bihun M (2003) The involvement of ethylene in the release of primary dormancy in Amaranthus retroflexus seeds. Plant Growth Regul 38:57-62

Kępczyński J, Bihun M, Kępczyńska E (2006a) Implication of ethylene in the release of secondary dormancy in Amaranthus caudatus L. seeds by gibberellins or cytokinin. Plant Growth Regul 48:119-126

Kępczyński J, Białecka B, Light ME, Van Staden J (2006b) Regulation of Avena fatua seed germination by smoke solution, gibberellin $\mathrm{A}_{3}$ and ethylene. Plant Growth Regul 49:9-16

Kępczyński J, Cembrowska D, Van Staden J (2010) Releasing primary dormancy in Avena fatua L. caryopses by smokederived butenolide. Plant Growth Regul 62:85-91

Lalonde S, Saini HS (1992) Comparative requirement for endogenous ethylene during seed germination. Ann Bot 69:423-428

Light ME, Daws MI, Van Staden J (2009) Smoke-derived butenolide: Towards understanding its biological effects. S Afr J Bot 75:1-7

Light ME, Burger BV, Staerk D, Kohout L, Van Staden J (2010) Butenolides from plant-derived smoke: natural plant-growth regulators with antagonistic actions on seed germination. J Nat Prod 73:267-269

Matilla AJ (2000) Ethylene in seed formation and germination. Seed Sci Res 10:111-126

Matilla AJ, Matilla-Vázquez MA (2008) Involvement of ethylene in seed physiology. Plant Sci 175:87-97

Naylor JM, Fedec P (1978) Dormancy studies in seed of Avena fatua. 8. Genetic diversity affecting responses to temperature. Can J Bot 66:2224-2229

Oracz K, El Maarouf-Bouteau H, Bogatek R, Corbineau F, Bailly C (2008) Release of sunflower seed dormancy by cyanide: crosstalk with ethylene signaling pathway. J Exp Bot 59:2241-2251

Stevens JC, Merritt DJ, Flematti GR, Ghisalberti EL, Dixon KW (2007) Seed germination of agricultural weeds is promoted by the butenolide 3-methyl-2H-furo[2,3-c]pyran-2-one under laboratory and field conditions. Plant Soil 298:113-124

Van Staden J, Jäger AK, Light ME, Burger BV (2004) Isolation of the major germination cue from plant-derived smoke. S Afr J Botany 70:654-659 